\title{
A IMPORTÂNCIA DOS CLÁSSICOS NA FORMAÇÃO DE PESQUISADORES: UM DIÁLOGO CONTEMPORÂNEO COM A TRADIÇÃO
}

\author{
Luciana Maria Schmidt Rizzi ${ }^{1}$ \\ Luciana Oltramari César ${ }^{2}$ \\ Miguel da Silva Rossetto ${ }^{3}$
}

Os clássicos são livros que exercem uma influência particular quando se impõem como inesquecíveis e também quando se ocultam nas dobras da memória, mimetizando-se como inconsciente coletivo ou individual. Italo Calvino (2007, p. 10)

\begin{abstract}
Resumo
O presente ensaio enfatiza a importância do rigor e da qualidade nas pesquisas em educação ao fomentar questionamentos relevantes na construção da pesquisa e da formação do pesquisador. O eixo nuclear desta proposição está no papel que os textos clássicos assumem tanto para a leitura interpretativa quanto para a elaboração textual, servindo, assim, como ponto de partida para o diálogo produtivo entre as problemáticas contemporâneas da formação humana e a tradição intelectual. $O$ ensaio pretende mostrar, também, o papel fundamental da hermenêutica como mediadora entre 0 texto, 0 pesquisador e a produção textual, enquanto metodologia promotora de intenso exercício de si sobre si. A presente pesquisa tem caráter bibliográfico, de cunho hermenêutico.
\end{abstract}

Palavras-chave: pesquisa em educação, hermenêutica, sujeito pesquisador, autoformação.

\section{THE IMPORTANCE OF CLASSICS IN THE TRAINING OF RESEARCHERS: A CONTEMPORARY DIALOGUE WITH TRADITION}

\section{Abstract}

The present study emphasizes the importance of the accuracy and quality in research in education by fostering relevant questions in the building process of the study and for the training of a researcher. The nuclear element of this proposition is on the role that the classic studies undertake to both interpretive reading and textual preparation, and thereby serve as a starting point for the productive dialog between the contemporary issues of the human formation and intellectual tradition. The study intends to show, as well, the hermeneutics vital role as mediator among the text, the researcher and the textual production, while

\footnotetext{
1 Universidade de Passo Fundo. Rua Osvaldo Kroeling, 349 Tapera/RS, CEP: 99490000. Imschmidt@hotmail.com

2 Universidade de Passo Fundo. Rua Bento Gonçalves, 1897, Passo Fundo/RS, CEP: 99020-060. lucianacezar@me.com.

3 Universidade de Passo Fundo. Rua Santa Terezinha, 322, Passo Fundo/RS, CEP: 99051-350. miguel.rossetto@upf.br.
}

Criar Educação, Criciúma, v. 8, no1, jan/jul 2019.- PPGE - UNESC 
methodology promoting an intensive exercise of itself on itself.The present research has a bibliographic purpose, having a hermeneutics purpose.

Keywords: research in education, hermeneutics, subject researcher, self-training.

\section{Introdução}

A formação do sujeito pesquisador é um desafio constante no decorrer do próprio processo de desenvolvimento da pesquisa. A pesquisa, em si mesma, não é, portanto, o único resultado esperado do exercício da pesquisa. Temos, em decorrência dela, a possibilidade de autoformação do próprio pesquisador. Em educação esta possibilidade tem alto impacto, pois o pesquisador é, frequentemente, o educador e, as práticas de pesquisa têm interferência direta nas práticas pedagógicas. Este contexto nos leva a ocuparmo-nos com a relação do pesquisador com os textos clássicos da tradição. Por isso, o presente artigo visa promover a reflexão acerca da qualidade da pesquisa em educação e do modo como esse processo se desenvolve no pesquisador quando pensado numa perspectiva hermenêutica.

O texto clássico mantém consigo a propriedade de conservar-se sempre atual e, por isso, em constante condição de diálogo com as novas gerações. Essa característica, que não lhe tira a erudição que é própria deste tipo de texto, exige um leitor/escritor forte, com condições de adentrar-se nos conceitos, noções e problemas que a obra apresenta. Porém, por outro lado, este mesmo "leitor forte" só se forma à medida em que realiza a pesquisa e insiste metodologicamente neste modelo de pesquisa. É um duplo movimento, ao passo em que o leitor se dedica hermeneuticamente ao texto, melhor consegue entender seus sentidos e, quando isso acontece, o pesquisador passa a formar a si mesmo.

Ademais, em educação este desafio se amplia, pois é imprescindível que a interpretação proveniente do contato com clássicos dialogue com os problemas educacionais da contemporaneidade. Este é o cenário, portanto, em que nosso problema de pesquisa se encontra: qual a importância dos clássicos na formação do pesquisador? Para tratá-lo, problematizaremos a importância dos clássicos nas ciências humanas, com vistas à fundamentação da pesquisa em educação, dandoIhe densidade intelectual, precisão conceitual, credibilidade e legitimidade. Além 
disso, propomos aprofundar a natureza da pesquisa bibliográfica em consonância com a perspectiva hermenêutica, modelo paradigmático para pensar sobre os princípios da autoformação do sujeito pesquisador.

\section{A constituição da pesquisa e do pesquisador através da leitura dos clássicos}

A pesquisa tem autoria, ou, deveria ter, minimamente, assinatura legítima e clara do pesquisador. Vimos, frequentemente, o pesquisador ser questionado sobre os impactos da sua pesquisa para a sociedade, para o mundo ou, pelo menos, para sua área de atuação. Nos acostumamos com esta preocupação influenciada, entre outros motivos, pelo forte pensamento positivista da primeira metade do século XIX em que o único conhecimento válido é aquele que agrega duas características fundamentais: a verdade purificada por um método que rejeita o mais possível a presença do pesquisador e; um conhecimento que tenha aplicabilidade e usabilidade para resolução imediata de problemas.

Deste modo, temos, primeiramente, a supremacia da verdade que, ao ignorar o sujeito, reserva-se a dissecar o objeto em si mesmo. Este tipo de verdade tem validade epistemológica em si mesma, justamente ao passo em que se distancia do sujeito e seu modo de vida. A primazia do método e da verdade oriunda da pesquisa afasta-nos da preocupação com o sujeito pesquisador.

Propomos pensar, então, a constituição da pesquisa enquanto constituição do sujeito. Mas, apesar de que, para fazer pesquisa, é essencial partir de uma problemática e, nesta linha de raciocínio, uma problemática que retrate o interesse do sujeito pesquisador, é preciso dizer que a pesquisa é um processo longo e não está necessariamente a serviço de solucionar questões imediatas do cotidiano. É todo um processo de construção do sujeito pesquisador, que vai em busca de fundamentos teóricos para desenvolver e aprofundar o seu problema e que, em uma primeira instância, busca precisão e rigor conceitual para a elaboração teórica, mas, num segundo momento, os reflexos desta busca podem, por vezes, impactar mais a competência de investigação do pesquisador do que a própria resolução do problema em si mesma. 
Evidente que a reflexão teórica mais profunda e ampla dá recursos e possibilidades de entendimento dos fenômenos, porém, por outro lado, oferta ao pesquisador uma posição crítica e de discernimento sobre a realidade, possibilitando assim uma solução singular, conforme a situação e o contexto em questão, bem como passa a constituir a subjetividade humana. A teoria assume aqui um papel vital tanto para a resolução do problema quanto para a formação do pesquisador. Ao mesmo tempo em que uma pesquisa pode ficar esvaziada de conteúdo e significado se não tiver uma formação teórica sólida, também o sujeito que investiga em nada sofre efeitos profundos em seu modo de ser e de pensar sobre a realidade. A precisão conceitual, a profundidade interpretativa e o rigor científico, bem como a relevância social, são a base para uma boa pesquisa. Por isso, salientamos a importância de se recorrer aos clássicos num diálogo com as problemáticas contemporâneas, pois os clássicos guardam em suas propriedades as características supracitadas.

André (2001, p.57) chama a atenção para o risco da "[...] supervalorização da prática e um certo desprezo pela teoria", o que é revelado na pesquisa à medida em que o investigador ocupa-se absolutamente com a resolução do problema, de modo imediato e privilegiado, em detrimento de um estudo sistemático e aprofundado de conceitos e argumentos. Entretanto, o autor alerta também para o processo inverso (2001), ou seja, ocupar-se demasiadamente com a teoria esquecendo-se de tratar da resolução do problema. É um desafio dar o devido valor a ambos, práxis e teoria, garantindo rigor conceitual e efetividade do conhecimento elaborado, pois o risco da dispersividade em um ou outro extremo é muito recorrente conforme as tendências do investigador.

Outro fator relevante na pesquisa refere-se ao domínio bibliográfico que constitui um dos fundamentos essenciais do pesquisador, dando o domínio de um repertório mais amplo, permitindo a "criatividade construtiva do pesquisador, seja na fundamentação do seu problema, seja na atribuição de significados aos dados" (2012, p.28). Para Gatti o domínio bibliográfico é o que permite "[...] a criatividade construtiva do pesquisador, seja na fundamentação do seu problema, seja na atribuição de significados aos dados" (2012, p. 28). Esta ampliação formativa e cultural, destacada pela autora, através de um domínio mais amplo da literatura clássica, permite uma ampliação de possibilidades de interpretações nos diferentes 
campos do conhecimento, e na pesquisa em educação, no que tange às Ciências Humanas.

Toda pesquisa percorre um caminho que vai da fase exploratória às etapas de construção do projeto, até os procedimentos para a entrada em um campo. Toda essa trajetória exige do pesquisador balizas teóricas para esse campo de elaboração científica. Para Minayo (2014) uma baliza importante ressaltada na construção da pesquisa e do pesquisador é o fato de que todo o pensamento está vinculado a uma ação. Nada pode ser intelectualmente e legitimamente um problema se não tiver sido um problema da vida prática. O interesse de pesquisa não nasce de forma espontânea, ele é fruto de uma determinada inserção social.

A pesquisa é um equilíbrio entre a invenção, a reflexão e a prova, uma operação que vai sendo construída e reconstruída conforme necessário, para produzir um conhecimento científico. O amparo do texto clássico nesse sentido é fundamental, pois dá um sustento teórico robusto. Deste modo, usar o saber teórico da tradição e dos clássicos contemporâneos, com teorias conceitualmente vigorosas como base para entender e analisar o fenômeno educacional, é um bom recurso na pesquisa.

O objeto real a ser pesquisado precisa passar por um processo que aproxima pesquisador, problema e teoria. Esse processo é imprescindível para que a pesquisa e o novo conhecimento ou novo modo de lidar com o problema possa, de alguma forma, impactar na transformação do sujeito. Desse modo, a leitura de uma obra clássica, com rigor e profundidade é fundamental para a qualificação da pesquisa e para a formação consistente do pesquisador.

A pesquisa passa a ter um caráter social amplo, sendo construída como processo, numa rede de saberes, convocando comunidades argumentativas para nos debruçarmos sobre os fenômenos que desejamos pesquisar. Ir aos textos clássicos também é um modo de pesquisa empírica, constitutivo da nossa experiência humana, num processo de crescimento e de amadurecimento pessoal.

Portanto, realizar uma pesquisa que tenha uma função social é, da mesma forma, ajudar a construir uma sociedade melhor. Desse modo teoria e a prática se retroalimentam, estão sempre em movimento, num vai-e-vem. Há uma tensão permanente entre teoria e prática, um enlace enriquecedor e complementar. A 
prática vai estar constantemente balizada e alimentada pela teoria, e a teoria vai estar a todo momento sendo posta à prova pela prática.

O texto que recorre aos clássicos tem uma potência de argumentação para dar conta de problemáticas complexas que nos interpelam e desafiam cotidianamente. Certamente a obra clássica traduz o espírito de um tempo histórico, está vinculada a uma tradição, porém, ela não se esvai no tempo, ela permanece e excede o autor. Cada pensador é influenciado pelas transformações da sociedade da sua época. Mas mesmo considerando que foi postulado em outro tempo e com características distintas da atual, há que se considerar o que de mais precioso a tradição nos legou. Os clássicos por serem clássicos, sempre têm algo a nos dizer sobre a realidade vivida.

É possível pensar os fenômenos contemporâneos, as problemáticas com que nos enfrentamos atualmente, seja no âmbito da educação, do social, da formação humana, com um diálogo vivo com a tradição, com os grandes pensadores. Para Dalbosco (2018), esse diálogo é fundamental e indispensável para embasar o surgimento do novo e salienta a importância do aprender com a experiência dos mais velhos e das gerações passadas, a importância de dar lugar à tradição. E ainda que recorrer a pensadores antigos não significa conservadorismo ou pensamento retrógrado, assim como recorrer somente aos contemporâneos não é sinônimo de atualização. Quem se ocupa profundamente com a pesquisa deveria privilegiar um diálogo entre a tradição e o novo para encontrar, com auxílio das teorias robustas, clássicas e novas, caminhos possíveis e modos de pensar as problemáticas do mundo contemporâneo, portanto, aceitar e valorizar o novo, sem abdicar da potência formativa que o clássico tem.

Italo Calvino em sua obra intitulada Por que ler os clássicos? nos convida a reflexão, em seu capítulo introdutório, sobre as razões que justificam a importância de um clássico e, consequentemente, motivam-nos a sua leitura. Para Calvino "um clássico é um livro que nunca terminou de dizer aquilo que tinha que dizer" como fonte inesgotável de motivação, que nos impele sempre à releitura (CALVINO, 1993, p. 11).

Ainda sobre as quatorze razões que justificam a importância do clássico, Calvino reforça o poder transformador que a leitura de obras de grande envergadura nos causa, marcando nossas vidas, ao longo de nossas trajetórias de formação 
como "uma influência particular quando se impõem como inesquecíveis e também quando se ocultam nas dobras da memória, mimetizando-se como inconsciente coletivo e individual" (1993, p. 10). Seu poder formativo está no fato de provocar no leitor transformações interiores para quem mantém contato com a obra. Assim, nunca mais somos os mesmos depois de lê-lo, relê-lo e tocá-lo, numa experiência formativa pessoal desenvolvida com paciência e disciplina.

Descreveremos, na continuidade deste ensaio, alguns princípios fundamentais para a construção da pesquisa em educação, assumindo assim a hermenêutica como papel fundamental na autoformação do sujeito pesquisador.

\section{O papel dos clássicos na construção da pesquisa e do pesquisador}

O texto clássico tem uma riqueza a transmitir e é imprescindível para se pensar a atualidade a partir de um modo de pensar que não é oriundo dos próprios problemas da atualidade. O clássico contribui, portanto, com uma lógica diferente de pensar da que está estabelecida na atualidade vivida. Isso é significativo, pois, uma vez que nos permite pensar à contrapelo, a teoria cumpre função desestabilizadora e, por isso, modificadora do sujeito pesquisador. Assim, devemos levar em conta a condição do sujeito pesquisador que aborda o clássico, pois não basta ler o clássico, é preciso que o sujeito pesquisador tenha condições de lidar com esse texto, o que perpassa pela capacidade de compreendê-lo e interpretá-lo. Para que um sujeito seja capaz de lê-lo e entendê-lo, é necessário um trabalho de preparação, de tradução e apropriação de sentidos. É preciso um preparo intelectual para que esse processo aconteça, sendo então o papel da análise de cunho hermenêutico fundamental no uso dos clássicos na pesquisa e na formação do sujeito pesquisador, na perspectiva de sua autoformação.

O poder transformador do clássico e a dedicação do leitor em desenvolver uma rigorosidade de insistência na leitura para compreensão da obra são destacados por Dalbosco (2018) como uma "experiência dolorosa". Ela exige renúncia, paciência e dedicação exaustiva, mesmo quando parecemos sucumbir, nocauteados pelo texto clássico.

Dalbosco sintetiza seus sentimentos: 
[...] a companhia frequente do clássico provoca-me um sentimento ambíguo: por um lado, de fraqueza e de impotência diante da grandeza cultural, da profundidade de pensamento e do encantamento das palavras que sua obra representa. Mas, por outro, sinto-me fortalecido porque justamente é esta grandeza que, uma vez passado o impacto inicial de sua leitura, leva-me a pensar sobre o mundo, e, ao pensá-lo, a refletir sobre mim mesmo e quem está a minha volta $(2018$, p. 6).

Nesta perspectiva, o desenvolvimento do sujeito pesquisador potente em educação exige uma força interna, capaz de nos tirar da zona de conforto para enfrentar a dureza da leitura exigida pelo texto, reconhecendo a profundidade do problema abordado pelo autor, sendo um mediador de sentidos. Dalbosco (2016) destaca que através da hermenêutica filosófica existem três princípios metodológicos potentes para compreender a tensão entre texto e leitor.

O primeiro princípio refere-se ao fio condutor do leitor com o suporte compreensivo através de uma prestação de contas histórico-conceitual. O princípio hermenêutico dos conceitos históricos deve ser confrontado permanentemente na sua pré-conceitualidade com os temas oferecidos para determinada obra filosófica pedagógica. Para Dalbosco esse princípio "leva o leitor a refazer-se a si mesmo, tendo que modificar suas crenças iniciais" (2018, p. 7).

O segundo princípio consiste "em entregar-se ao texto, escutando o que ele tem a dizer e deixando-se impregnar pelo processo de estranhamento que ele causa" (2018, p. 7). Para o autor, sem o silêncio e a escuta não ocorre a fusão necessária do texto, como aspecto indispensável para a compreensão.

Como princípio final e embasado no segundo, a leitura precisa responder suas perguntas, através da escuta ativa exercida, pelas próprias questões que 0 texto traz. A capacidade de profundidade da leitura repousa na capacidade do leitor de realizar novos questionamentos.

Portanto, para Dalbosco:

Desleitura, por sua vez, é o efeito que a obra provoca no leitor atento, impulsionando-o a pensar por si mesmo. Com a leitura atenta da obra, impregna-se do estilo literário do autor e com sua forma própria de pensar. Aprende não só a desenvolver pensamentos, mas a trabalhar de modo paciencioso consigo mesmo. A desleitura da obra clássica proporciona, além da experiência intelectual consistente, também a genuína experiência formativa que conduz ao vagaroso trabalho de si sobre si mesmo. Ler um clássico é, neste sentido, desfrutar da possibilidade de reinventar a si mesmo (2018, p. 9). 
De outra parte, o acesso ao texto clássico é uma das tarefas mais difíceis. Aqui merece destaque o trabalho pedagógico a ser desenvolvido, cujo acesso depende, em boa parte, da distância que separa o conteúdo do texto, o aporte cultural e a capacidade simbólica do iniciante e, por outro lado, do bom preparo do professor como hermeneuta que fará a mediação introdutória entre texto e leitor.

Na perspectiva do texto clássico, ele apresenta a genialidade de seu autor, acompanhado do trabalho árduo e longo de um exercício meditativo. Pode ser descrito como a síntese cultural de uma época, com grandes tendências intelectuais e científicas. Também é preciso levar em conta, o estilo linguístico e a capacidade intelectual do autor. Isso revela que o clássico não é sinônimo de facilidade, provocando no leitor certo estranhamento e até certa impotência frente ao texto.

$\mathrm{Na}$ hermenêutica, o ser humano é pensado como um decifrador de sentidos subjacentes de um texto, podendo traduzir e interpretar, tornando-o inteligível, a partir da sua capacidade simbólica, como refere Dalbosco: "A melhor definição do sujeito pesquisador talvez seja mesmo a de um tradutor de sentidos. Ao se pôr a campo ou ao abrir algum livro, o tradutor se vê imediatamente frente a enorme e difícil tarefa de decifrar e verter sentidos" (2017, p. 4).

Para Dalbosco (2011, p.17), "é preciso colocar o preparo do educador e sua tarefa como mediador entre o texto clássico e o leitor no centro do problema", reforçando assim, o papel da intervenção pedagógica no processo formativo do leitor e do pesquisador.

Da mesma forma, um professor capaz de conduzir essa imersão no universo da cultura elaborada, denota uma experiência bem conduzida, capaz de:

[...] emergir a exigência ao estudante de que o trabalho de condução do professor não deveria substituir seu esforço pessoal de leitura do texto e de enfrentamento das dificuldades disso resultantes. Sem a exigência de tal experimentação própria do estudante, qualquer pretensão pedagógica do educador visando sua autonomia ficaria certamente prejudicada, constituindo um paternalismo prejudicial e inaceitável (2011, p.17). 
Fazer pesquisa em educação é, por consequência, pensar a formação do sujeito pesquisador sobretudo com o aporte nuclear na condição histórica e humana. Neste sentido, a hermenêutica contemporânea representa uma das principais tradições de pesquisa, através da autocompreensão do sujeito, em sua relação com o mundo. A relação entre intérprete e texto é pensada na perspectiva autoformativa do sujeito pesquisador. Para isso, usamos as palavras de Dalbosco que, pensando nessa perspectiva, reforça esta afirmação ao descrever que "o que conta é a historicidade, contextualidade e intersubjetividade do sujeito enquanto busca constante e inesgotável, sempre sujeita a riscos" (2017, p .2).

O autor ainda refere que o sentido compreensivo do sujeito não é fixo, tem uma historicidade, "quem o faz é sempre o sujeito pesquisador, o qual não pode excluir do processo investigativo sua própria condição de ser humano" (2017, p. 9).

Nesta construção do pesquisador (leitor/escritor) passamos, primeiramente, ponderando por algum tempo uma ideia a ser pesquisada. Há um processo preparatório e indispensável de construção de uma ideia. São reflexões sobre o conteúdo do trabalho futuro muito antes de dar uma forma definitiva. "Andar grávido de uma ideia" é uma metáfora interessante usada por Flickinger (2010, p.11), num processo de esclarecimento interno, levado a efeito ainda antes de se começar a escrever.

Então segue-se o próximo passo: transmitir o conteúdo de nosso esforço mental por formulações adequadas de linguagem. Quanta decepção se experimenta no momento de tentar dar forma ao pensamento, escrevendo, representado em palavras, conceitos e frases. Transpor ao papel a ideia intuída não é tarefa fácil. Flickinger (2010) fala da importância de se buscar conceitos adequados para dar coerência às ideias, pois os conceitos também proporcionam um pensamento adequado.

Os momentos ditos irracionais fazem parte do processo de escrever e participam na evolução do conteúdo e do sentido de um texto escrito. A produtividade do processo de escrever deve-se a oscilação incessante, ao vaivém entre os esboços de sentido intuídos, os momentos perturbadores inerentes à própria linguagem, ao sentido do texto. Flickinger (2010, p. 15) designa esse processo de "lógica clandestina do compreender". Nesse sentido, entra aqui o que se concebe pela tradição das ciências humanas como hermenêutica: compreensão 
do que se passa no processo do pôr-por-escrito um pensamento intuído. É todo um trabalho de compreensão e reflexão do texto teórico estudado, um exercício hermenêutico e crítico para a compreensão do pensamento dos autores consultados. A ideia é confrontar o autor e a teoria num trabalho de apropriação, como aponta Minayo:

Na pesquisa bibliográfica se deve destacar as teses, as categorias centrais, os conceitos e as noções e como tudo isso se concatena no discurso do autor. É preciso, também, destacar os pressupostos teóricos e as razões práticas que subjazem aos trabalhos consultados. É importante que o investigador não se esqueça de que toda a teoria é um discurso estruturado em proposições baseadas em teses, hipóteses, conceitos, categorias e noções. (...) O marco teórico de uma pesquisa não se sustenta num discurso composto pelo desfile dos autores consultados. Ao contrário, deve constituir-se na construção de uma síntese na qual o investigador expressa suas próprias ideias, pressupostos e hipóteses (MINAYO, 2014, p. 185).

Esses momentos irracionais tem um caráter duplo - não são atrapalhadores que impediriam a escrita em expressões adequadas, mas esse vaivém que permite a constituição de sentido e a criação do texto escrito. Um processo de escrever é uma tensão entre o pensamento intuído e a configuração concreta do sentido apresentado pelo texto (FLICKINGER, 2010), que pode ser considerada uma tensão produtiva.

O trabalho elaborativo do pesquisador consiste em transpor a ideia articulada para a linguagem. Esse trabalho intelectual desenvolvido pelo pesquisador nasce a partir da tensão subjetiva que implica a articulação entre a ideia e a linguagem que, por consequência, resultar no texto escrito e, por isso, num processo de apropriação. Mesmo assim, o pesquisador não comanda todas as possibilidade ou fragilidades deste processo criativo, pois, como nos diz Flickinger, "a hipótese de um sujeito cognitivo capaz de dominar, de modo autônomo, o processo de produção do sentido deve ser colocada em xeque" ( 2010 , p. 17), já que isso seria a morte do próprio caminho hermenêutico da pesquisa, o qual não pretende encerrar todas as possibilidades de conhecimento ou produção de sentido.

Por meio da insistência da ideia de objetividade do processo de conhecimento, o sujeito conhecedor imuniza-se para não se confrontar com sua própria competência restrita. Abdicar da ideia de ser-senhor-de-si afeta a vaidade. $\mathrm{O}$ 
sujeito, em um processo legítimo de pesquisa, tem que rever suas certezas e isso é produtivo. Flickinger (2010, p.19) chama isso de o lado produtivo do fracasso do modelo de um sujeito auto-suficiente.

Então não é um processo linear de produção do pensamento objetivado no texto, mas um papel próprio do sujeito em desenvolver-se e de auto esclarecimento do sujeito-autor ao longo da elaboração do seu texto. O autor se entrega a uma experiência surpreendente mesmo que tensa e decepcionante. Uma aventura imprevisível. Seria como gestar e parir uma ideia, ter pensamento e capacidade de articulação da teoria, dos conceitos e da experiência prática (FLICKINGER, 2010, p.20).

Essa experiência promove uma compreensão intelectual verdadeira. Mostra o papel do homem dentro desse processo. Há que ter disposição de suspender, de abrir mão dos pressupostos racionalistas ante o inesperado da experiência com a linguagem, estando aberto às configurações surpreendentes de imprevistos. Não é um mero meio de transferência de conteúdo. Os processos hermenêuticos, que são a compreensão e produção de sentido, somente podem se dar com essa tensão constitutiva entre a pretensa autonomia do sujeito-autor e a produtividade originária da linguagem. Segundo Flickinger (2010, p. 22-23), essa seria a verdadeira racionalidade do pensar.

Dalbosco utiliza a metáfora de "tradutor de sentidos" ao sujeito pesquisador, ou seja, ele assume "a tarefa de intercambiar comunicativamente mundos entre si diferentes, fazendo emergir o sentido e o interesse que os constituem" (2017, p.5). Do ponto de vista da hermenêutica, o mais importante neste processo é o trabalho incansável da mediação pedagógica, fazendo a aproximação ao que parece estranho e inatingível, numa postura de escuta, serenidade e moderação. Tal capacidade só é possível através de uma intensa solidão intelectual capaz de cumprir com seu exercício de elaboração teórica.

Por consequência, o aporte da hermenêutica faz-se notar na formação do sujeito pesquisador, por meio de princípios, dos quais Dalbosco (2017) destaca em seus escritos, a saber: a exigência de pôr em questão suas próprias pressuposições; a apropriação conceitual vagarosa; o uso da pesquisa bibliográfica como maneira adequada para a interpretação do texto; o diálogo como princípio metodológico fundamental entre o autor e o leitor; saber ouvir o texto com o propósito de ir além 
de seu próprio sentido; a fusão de horizontes como forma de enfrentar a tensão constitutiva à interpretação dialógica (contemplando a falibilidade e a historicidade do conhecimento humano); levar em conta a natureza epistemológica e metodológica da interpretação (numa postura interpretativo-dialógica do sujeito pesquisador) e, por último, a necessidade de vincular a interpretação do sentido do texto ao problema de investigação.

Este percurso elaborado para a formação do sujeito pesquisador, pensado na perspectiva hermenêutica, precisa enfrentar a tensão dialógica entre o texto e o leitor, transformando-se num processo de autoformação, uma vez que é resultado de um trabalho intenso que o sujeito realiza sobre si mesmo. Encontramos, desta forma, no trabalho hermenêutico a potência e o poder transformador do próprio sujeito ao enfrentar a leitura de um clássico.

\section{Considerações finais}

Os desafios enfrentados no campo da pesquisa em educação são muitos e permeados por modificações políticas e sócio-culturais no mundo, na contingência de novas vozes, de grupos diversificados, que ganham espaços e abalam as nossas crenças sobre o papel da educação. A leitura e a interpretação da obra clássica pode dar sustento ao usar esse saber teórico como base para enfrentar e compreender os problemas contemporâneos. Para tanto há a necessidade de um rigor conceitual, um estudo hermenêutico.

O pesquisador não pode ser apenas um discípulo, no sentido de um repetidor de discursos sem ter crítica e sim, poder pensar a prática a partir da teoria, num trabalho de apropriação de conceitos. Reforçamos, deste modo, o papel que a leitura hermenêutica dos textos clássicos e a postura metodológica assumem neste processo de construção da pesquisa e do pesquisador, atento e capaz de dialogar com a tradição, como suporte indispensável para potencializar a compreensão da atualidade através de um exercício de imersão na tradição intelectual, num diálogo permanente do leitor com o texto e com a atualidade.

A leitura dos clássicos não pode ser oferta de garantias úteis, como destaca Ordine (2016), mas uma forma de conquistar e defender a nossa dignidade de seres humanos que nos é oferecida pela cultura e educação livre. Ainda, para o autor, ao 
reforçar a importância que os clássicos e a formação exercem, revela que eles "[...] podem nos ajudar, de qualquer modo, a resistir, a manter acesa a esperança, vislumbrar aquele raio de luz que nos permita percorrer um caminho digno" (p. 27). Esse caminho pode nos impedir de produzir uma coletividade doente e sem memória.

Cabe-nos então, referenciar o caráter inesgotável do clássico na produção da pesquisa e na construção do pesquisador, num fortalecimento da convicção teórica pelo diálogo entre a tradição e a atualidade. Esta capacidade mostra a força intelectual do leitor, com disposição para enfrentar essa exigente companhia, produzindo um sentimento de transformação.

Reforçamos, desta forma, o papel que a hermenêutica exerce neste processo de formação, como uma das modalidades mais adequadas para a compreensão e interpretação dos fenômenos e, como uma possibilidade real de enfrentar os desafios éticos e epistemológicos da ação.

Concluímos, ao final do ensaio, o forte poder de transformação de si mesmo e enriquecimento intelectual que os textos clássicos promovem no pesquisador. Fazendo uso das palavras de Isaac Newton para corroborar com nossos escritos: "se conseguimos ver mais longe é porque estamos aos ombros de gigantes".

\section{Referências}

ANDRÉ, Marli. Pesquisa em Educação: buscando rigor e qualidade. Cadernos de Pesquisa, n. 113, p. 51-64, jul. 2001.

CALVINO, Italo. Por que ler os clássicos. São Paulo: Companhia das Letras, 1993.

DALBOSCO, Claudio A.; Casagranda, Edson. Educação em sociedades tradicionais e sociedades complexas: o problema da crise de autoridade. In: MÜHL, E.

H.;DALBOSCO, C. A.; CENCI, A.V. (Org.) Questões atuais da educação:

sociedade complexa, pensamento pós-metafísico, democracia e formação humana. 1ed.Ijuí: UNIJUÍ, 2016, v. 1, p. 51-78.

DALBOSCO, Claudio A. Plasticidade da condição humana e educação. Passo Fundo: texto não publicado, 2018.

DALBOSCO, Cláudio A. Filosofia e Educação no Emílio de Rousseau: o papel do educador como governante. São Paulo: Editora Alínea, 2011. 
DALBOSCO, Cláudio A. Filosofia da Educação e formação do sujeito pesquisador: alguns aportes hermenêuticos. 38 Reunião Nacional da ANPEDUFMA - São Luis do Maranhão, 2017.

ESTEBAN, Maria Paz Sandín. Pesquisa qualitativa em educação. Porto Alegre: AMGH, 2010.

FLICKINGER, Hans-Georg. A caminho de uma pedagogia hermenêutica. Campinas: Autores Associados, 2010.

GATTI, Bernardete. A construção metodológica da pesquisa em educação: desafios. RBPAE, v. 28, n. 1, p. 13-34, jan./abr. 2012.

MINAYO, Maria Cecília de Souza. O desafio do conhecimento. São Paulo: Hucitec, 2014.

ORDINE, Nuccio. A utilidade do inútil. Tradução de Luiz Carlos Bombassaro. Rio de Janeiro: Zahar, 2016.

Recebido em dezembro 2018 Aprovado em março 2019 